\title{
Getting depleted resource-based cities back on their feet again-- the example of Yichun in China
}

Chang $\mathrm{Yu}^{\mathrm{a}}$, Martin de Jong ${ }^{\mathrm{b}, \mathrm{c}}$, Baodong Cheng ${ }^{\mathrm{a}, *}$

a. School of Economics and Management, Beijing Forestry University, No.35 Tsinghua East Road Haidian District, Beijing, China

b. Faculty of Technology, Policy and Management, Delft University of Technology, Jaffalaan 5, 2628 BX Delft, the Netherlands

c. Faculty of International Relations and Public Affairs, Fudan University, No.220, Handan Road, 200433 Shanghai, China

Email: chang.yu.v@gmail.com,W.M.deJong@tudelft.nl,baodongcheng@126.com,

*Corresponding author: Tel: +86 1062337245

Keywords: sustainable development, resource-based city, forestry city, eco-efficiency, China

\begin{abstract}
Sustainable consumption and production (or lack thereof) can leave very distinct marks at the city level. Among the cities aiming at sustainable development, resource-based cities (RBCs) are of special concern due to the tight interrelations economy, urban development, natural resources and environmental context have in them. Excessive exploitation and inefficient resource utilization often cause pollution and ecological risks. As natural resources are getting exhausted, their resource-based industries will collapse, threaten wider urban development and lead to economic recession. In this article, we focus on the economic and ecological dilemmas that the RBCs face in China. We first present an overview of China's policy implementation for rescuing and transforming RBCs. Then a particular RBC, Yichun, which is classified as "recessionary", is analyzed to understand the challenges that it faces during its transition. The method of eco-efficiency is used to uncover Yichun's environmental performance in relation to its economic development. Subsequently, we explore the barriers in terms of industrial transformation, conflicts between national, provincial and local governmental actions, and the effects of the circular economy in Yichun. At the end of this article, we formulate several recommendations to facilitate Yichun's sustainable development. We propose that Yichun specifically needs to consider the energy consumption and pollution when selecting alternative industries. Furthermore, one-size-fits-all policies do not help to solve the problems in Yichun. Policies need to be contextualized locally through well-reflected coordination between higher and lower tiers of government.
\end{abstract}

\section{Introduction}

The concept of sustainable consumption and production (SCP) was proposed at the Rio Summit (The United Nations Conference on Environment and Development) in 1992 and specified at the Oslo Symposium in 1994. Since then, SCP has been aimed at improving the efficiency of resource consumption in the production, distribution and product usage, in order to decouple economic growth and environmental pressure for realizing sustainable development (Clark, 2007; Tukker et al., 2008). The actions regarding SCP at the city level have been emphasized in the transition towards sustainable cities. In China, the idea of developing sustainable cities has been vigorously promoted. The related programs, such as those for eco-cities and low carbon cities, intend to solve the pollution, inefficient use of energy and resource caused by rapid urbanization and industrialization (de Jong et al., 2013; 
Wu, 2012). As Schroeder (2014) pointed out, the overwhelming urbanization in China has caused significant impact on resource consumption, the balance in ecological systems and the health of citizens. Indeed, a number of cities in China are confronted with ecological and environmental crises that even hinder their economic and social development. Among these cities, resource-based cities (RBCs) are of special concern. RBCs are defined as those cities the local economy and industries of which mostly depend on the exploitation and primary processing of natural resources (Bradbury and St-Martin, 1983; Li et al., 2013), for instance, coal mining, oil and forestry. In China, the natural resource industries in RBCs are mainly extractive and primary industries which produce low added value and cause serious pollution and ecological degradation. Solely relying on resource industry limits the development of other alternative industries to diversify the structure of the economy and employment. As natural resources are getting exhausted, the resource-based industries will fall into recession and generate massive unemployment (Sachs and Warner, 2001). The poor economic situation adversely affects public services such as education and health care. Subsequently, local inhabitants may move to other cities and leave decaying communities behind. However, urban communities are vital to generate sustainable production and consumption because they are part of the urban industrial system as consumers and producers. The development of RBCs cannot be promoted without community efforts. Furthermore, excessive exploitation and inefficient resource utilization have caused pollution and ecological risks due to a lack of scientific input on how wisely to use the resources. In that sense, RBCs are facing even more serious crises than other cities in terms of sustainable development: their economy, urban development, natural resources and ecological situation are tightly interrelated.

The research on the sustainable development of RBCs dates back to the 1970s. Canadian scholars investigated a host of single-industry towns and resource-dependent communities. They used a sixstage life cycle model to describe the development from construction, recruitment, transition, maturation, recession and extinction (Bradbury, 1979; Lucas, 1971). Due to these special development patterns of RBCs, measures and policies should be prepared in the stage of maturation to facilitate alternative industries, in order to prevent recession and extinction. Some RBCs carried out timely measures to transform their "single industry model" and successfully recovered their economy, such as the Ruhr area in Germany, Kitakyushu in Japan and Lorraine in France. Table 1 presents the regional policies of the Ruhr as an example to indicate the goals of policies in the different periods of transformation (Percy, 2003). The Ruhr was a coal mining region that successfully recovered its economy and transformed itself from a resource-based industrial region to become the largest industrial area in Germany with diverse industries and cultural centers. The transformation benefited from appropriate planning and timely policy intervention in the different stages.

(Table 1 is inserted here.)

Sustainable development of RBCs in China also attracts academic attention. Yu et al. (2008) calculated the degree of sustainable development of mineral resources in 78 mining cities in China. Their research results indicated the interrelations between sustainability and the features of mining cities (e.g., geographical location, city size and type of natural resources). Similarly, the eco-efficiency of 16 resource based cities was evaluated by $\mathrm{Li}$ et al. (2010) to analyze the major influencing factors. Furthermore, the role of local authorities and administrative approaches was analyzed by Liu et al. (2012) in the establishment of new urban centers in a Chinese resource exhausted city. They argued that local government has a key impact in rescuing the economy of resource exhausted cities. Li et al. (2013) summarized the transition policies and government actions for Chinese RBCs. They concluded that the main reasons why RBCs are less developed are the after-effects of the planned economy, 
unreasonable tax systems, planning mistakes and misguided resources exploitation policies. Different types of RBCs should get customized policies. Financial aid from central government is crucial, but unfortunately it is based on general averages which do not take local economic conditions into account. It may lead to uneven development and social tensions ( $\mathrm{Li}$ et al, 2013). The above mentioned studies highlighted a variety of solutions to attract new industries and restructure the labor market in order to stimulate local economies within RBCs.

However, the specific dilemmas that exist between economic development and environmental preservation in RBCs have not been discussed in detail. On the one hand, environmental protection and ecological restoration require financial support for technological improvement, industrial transformation, and the relocation and retraining of employees. Unfortunately, many RBCs cannot afford the financial expenditure to realize these goals because of their relatively backward economic position. On the other hand, the eagerness for new economic gains may drive them to lower their environmental standards and accept polluting projects, which is exactly what has happened in many industrial areas in China (Tian et al., 2014; Zhang et al., 2010). It may enhance the economy for a short period, but at long last bog down RBCs into new other mires. Sacrificing environmental quality for higher gross domestic product (GDP) and employment in RBCs may damage their long-term urban sustainable development ( $\mathrm{Li}$ et al., 2013). So far, we have not seen much research regarding these dilemmas for RBCs in the literature, and it will be our focus here.

The research goal of this research is to understand the tensions that arise between economic development and environmental preservation during the transition of RBCs. This outline of this article is as follows. In section 2, an overview of China's policies for rescuing and transforming RBCs will be examined. In section 3, our research methods and data collection will be introduced. We will analyze a specific example of RBCs: Yichun, a forestry city in Heilongjiang province. Yichun incarnates many of the problems RBCs experience. Efforts have been made to direct Yichun's transition towards one of sustainable development; however, the results are not overwhelmingly positive. The detailed case will be discussed in section 4. We will first introduce the general context of Yichun city. Second, the method of eco-efficiency will be used to analyze Yichun's economic and environmental performance between 2005 and 2013. This method has been widely used to evaluate changes in regional and national environmental pressures during economic growth (Seppäläa et al., 2005; Wang et al., 2011; $\mathrm{Yu}$ et al., 2013). Third, we will explore the barriers in Yichun's transition towards sustainable development. In section 5, we will conclude with several recommendations to facilitate Yichun's transition and shed light on sustainable development in RBCs in China.

\section{China's policies for re-developing RBCs}

In China, RBCs thrived in the aftermath of rapid discovery and exploitation of natural resources for promoting heavy industries. They began to experience problems from the 1980s onwards and became active concerns of the government since 2000s. Before the 1980s, the central government allocated the production of raw materials and energy produced in these RBCs to the eastern coastal regions, which they did at a low price. The large resource companies (e.g., mining, forestry and oil) were state-owned companies that handed over major tax income to the central government rather than to local governments. As natural resources began to get exhausted, many resource exploitation companies closed down, leading to high unemployment. However, the local governments did not have enough revenue to provide social welfare, ecological restoration and urban development (Li et al., 2013; Long et al., 2013). Relying on natural resources had limited the development of other alternative industries, which made it difficult to sustain economic growth and offer alternative employment. Moreover, ecological degradation in many RBCs has been alarming. The surrounding water, soil and ecology are 
jeopardized because of extensive over-exploration and unsophisticated environmental management. Industrial pollution (e.g., $\mathrm{SO}_{2}$ emission, waste water, chemical oxygen demand) has grown significantly. Other ecological risks, such as deforestation and land subsidence, have been frequently reported in cities dominated by forestry and coal mines (Yu et al., 2011).

In 2002, the $16^{\text {th }}$ National Congress Report highlighted the importance of the development of new and alternative industries in RBCs. This was the first political requirement from central government to rescue them. Subsequently, in 2005 five RBCs in Northeastern China were nominated as pilots to solve poverty, unemployment and environmental problems, including Yichun, Daqing, Fuxin, Shuangyashan and Liaoyuan. In order to expand this policy to the whole country, in 2007 several suggestions were made by China's State Council to promote the sustainable development of RBCs. Two batches of in total forty-four resource-exhausted cities were nominated in 2008 and 2009 as focal areas. A series of supporting policies and subsidies were issued to compensate and recover the damaged natural environment, promote alternative industries and social security (State Council, 2007).

In 2013, the State Council issued its plan on the sustainable development of resourced-based cities from 2013 to 2020 (State Council, 2013). The latest list of 262 RBCs was announced, including 126 prefecture-level cities, 62 county-level cities, 58 counties and 16 municipal districts. Fig.1 illustrates the distribution of these cities across the country. It shows that Northeast, Central and Southwest China have a higher density of RBCs. In these 262 cities, the main natural resources are coal (Central China) and forest (Northeast China), and the rest includes oil, ferrous metallurgy and nonferrous metallurgy. The added value from exploiting natural resources accounts for $25 \%$ of all added industrial value, which is twice as high as the national average. However, the proportion of the tertiary industry is $12 \%$ lower than the national average. It implies that extractive industries still carry heavy weight in the industrial structure. The plan of State Council classified the RBCs into four categories: growing, mature, recessionary and recovered. The location and density of the four types of RBCs across the nation can be seen in Fig 2. 40\% of the growing RBCs are located in Northwest China. Mature RBCs can mainly be found in Southwest China and Central China. Regarding the recessionary RBCs, Northeast China and Central China take $28 \%$ and $25 \%$, respectively. Moreover, $31 \%$ of the recovered RBCs are located in East China. Table 2 indicates the role and specific goals allocated to the four types of RBCs in terms of sustainable development according to State Council (2013). In general, the incentive policies will be implemented to adjust industrial structures, improve people's livelihood, and treat and restore the environment.

(Fig. 1 is inserted here.)

(Fig.2 is inserted here.)

(Table 2 is inserted here.)

\section{Research methods and data collection}

The goal of this research is to understand the barriers in the transition of RBCs. We have selected a forestry resource city, Yichun, for in-depth investigation. The main criterion for selecting Yichun is that it has exposed most of the problems a resource-exhausted city can have, such as a sharp decrease in remaining available forestry resources, economic recession in the forestry industries and massive unemployment. Moreover, the deforestation and inefficient wood processing have jeopardized the ecological function of the forest in the whole eco-system. Yichun has begun to implement a transition from the 2000s onwards in terms of forestry land recovery, promotion of alternative industries, environmental protection and pollution control. But the effects have thus far not been very significant. 
The analysis of the difficulties Yichun faces may offer useful lessons for the sustainable development of other RBCs.

We will first introduce the general context of Yichun city and discuss the problems it is confronting. Second, we will explain how we deploy the method of eco-efficiency to this case; it can reveal the relations between environmental pressures and economic performance and thus help us to measure a region's sustainable development (Seppäläa et al., 2005; Wang et al., 2015). The expression of ecoefficiency is often presented as the ratio between economic value added (e.g., GDP and industrial added value) and environmental influence added (e.g., energy consumption and air emission) (Huppes and Ishikawa, 2005). Eco-efficiency has been used to evaluate the sustainability in the forestry industry before. For instance, Koskela (2015) discussed the measurement and data suitability of ecoefficiency in the Finnish forestry industry. The indicators of sulfur dioxide $\left(\mathrm{SO}_{2}\right)$, nitrogen oxide $\left(\mathrm{NO}_{\mathrm{x}}\right)$, chemical oxygen demand (COD), waste and value added were selected to present the ecoefficiency of Finnish forestry industry between 1998 and 2005. The relationship between environmental regulation and eco-efficiency in the pulp and paper industry was examined by Wang et al. (2011) in Shandong province, China. They selected the eco-efficiency indicators of energy and water consumption, $\mathrm{COD}$, ammonia nitrogen $(\mathrm{AN}), \mathrm{SO}_{2}$, dust and carbon dioxide $\left(\mathrm{CO}_{2}\right)$. These studies presented the usability of eco-efficiency to analyze the environmental influence relative to economic growth in forestry regions. We will analyze Yichun's eco-efficiency performance. When selecting the eco-efficiency indicators, we refer to the indicators mentioned above to analyze forestry regions, and also consider the data acquisition from field research. Thus, the indicators we selected include resource consumption and environmental pressure. The efficiency of resource consumption involves energy and water consumption. Environmental pressure indicators involve the emissions of wastewater, $\mathrm{COD}, \mathrm{AN}, \mathrm{SO}_{2}, \mathrm{NO}_{\mathrm{x}}$, dust and solid waste. We collected the data from Yichun Statistical Bureau, Yichun Statistical Yearbooks (2010-2013), Yearbooks of Development of Heilongjiang During 60 Years (1949-2009), and Heilongjiang Statistical Yearbooks (1980-2013).

Third, we would like to discuss the challenges in Yichun's transition towards becoming a sustainable city. In China, to transform an RBC facing economic recession, local government needs to take the lead in stimulating this process with strong top-down measures (Dong et al., 2007; Li et al., 2013; Schroeder, 2014). Thus, we focus on the role of local government and the difficulties it has when implementing the policies. We have conducted a series of open interviews with several local officials mainly from Yichun's Environmental Protection Bureau (EPB), Development and Reform Commission (DRC), and its Industry and Information Commission. The questions are listed in Appendix. These interviews were invaluable in helping us to understand the challenges and barriers Yichun is faced with during its transition.

\section{The example of Yichun in China 4.1 General context of Yichun city}

Yichun is the most important forestry-based RBC in China. It is located in Heilongiiang province (Fig.3), occupies $32,759 \mathrm{~km}^{2}$ and has a population of 1.27 million. $83.4 \%$ of Yichun's land area is covered by forest. The forestry working circle counts nearly 4 million hectares. Overall, Yichun's GDP per capita has annually increased between 1980 and 2012 with an average rate of $11 \%$, but it remains lower than that of Heilongiiang province (Fig.4). In 2005, Yichun was listed by the State Council as a pilot for RBC economic transition. In the plan on sustainable development of RBCs mentioned in section 2, Yichun is classified as "recessionary", which means that the main goals of Yichun are to promote alternative industries and to improve its economic and employment situation. 
(Fig. 3 is inserted here.)

(Fig.4 is inserted here.)

As a typical forestry resource city, Yichun became prosperous and recessionary following the fate of its forestry industry. Between 1958 and 1980, Yichun's economy grew significantly because of vast timber production. Timber output was more than 5 million $\mathrm{m}^{3}$ per year. During this period, the added value of logging industry accounted for over $60 \%$ of its GDP growth. However, excessive exploitation caused a sharp decline of $50 \%$ of its forest stock volume. The volume of recoverable forest decreased by $95 \%$. Most of the forest farms even had no wood left to cut. The economic crisis was exposed between 1980 and 1994 due to the severe deforestation. After over-relying on the timber industry, many wood processing companies then had to shut down. Until 1989, the cumulative losses of the timber industry had reached 0.53 billion $\mathrm{RMB}^{1}$ and the total liabilities had reached 7.8 billion RMB (Yichun, 2009). As Fig. 4 shows, Yichun's annual GDP growth rate hit the bottom of $-9.42 \%$ in 1990 . The average GDP growth between 1980 and 1994 was only 5\%. Another economic downturn happened between 1998 and 2002 because of the prohibition order to cut natural forest issued by the Natural Forest Protection Project (SFA, 2000). The wood related industries were significantly affected. In 2010, this national protection project was implemented for a second term to recover forest and ban final felling. Since April 2014, the forest regions in Heilongiiang province have been required to stop commercial logging altogether. This will indirectly affect the employment of 80,000 people in Yichun. The prohibition orders and the economic distress both drove Yichun to reduce its forest industry and transform the city in a sustainable way.

(Table 3 is inserted here.)

\subsection{Eco-efficiency of Yichun}

In this section, we will evaluate the efficiency of the resource consumption (i.e., energy and water consumption) and the efficiency of the environmental pressure indicators (i.e., wastewater, COD, AN, $\mathrm{SO}_{2}, \mathrm{NO}_{\mathrm{x}}$, dust, solid waste) in Yichun.

Fig. 5 shows that the efficiency of energy and water consumption has risen. Compared with 2005, energy efficiency increased by $54 \%$ in 2013 . The biggest energy consumer in Yichun is the West Forest Iron and Steel Group (WFISG) accounting for three quarters of total energy consumption and generating a quarter of Yichun's GDP. As the major target, WFISG has upgraded its equipment to recover gas from the production of blast furnaces. Besides, a generator set of 18,000 kilowatts has been built, which reduces coal consumption by 100,000 tons per year and generates 80,000 kilowatt hours of electricity. The energy conservation of WFISG received a reward of 1 million RMB from the Heilongiiang provincial government. Apart from improving the efficiency of traditional energy, new energy resources are also promoted by Yichun's local government, especially wind and hydro power. So far, 11 wind power farms with an installed capacity of 409,000 kilowatt hours are in operation and produce electricity of 0.8 billion kilowatt hours per year. 10 small hydropower stations with installed capacity of 24,700 kilowatts have been built, which accounts for $2.61 \%$ of the total exploitable amount (Yichun DRC, 2014a).

(Fig. 5 is inserted here.)

\footnotetext{
${ }^{1} \mathrm{RMB}$ is Chinese currency. $1 \mathrm{RMB}$ is approximately equal to 0.16 US dollar.
} 
Water efficiency saw an obvious growth in 2005 and this continued until 2012. In 2013, it dropped by $12.9 \%$. Regarding the indicators of pollution, the total emissions of $\mathrm{COD}, \mathrm{AN}, \mathrm{NO}_{\mathrm{x}}$ declined annually by $14.1 \%, 1.8 \%, 5.3 \%$ in 2013, respectively (Yichun EPB, 2014). The total emission of $\mathrm{SO}_{2}$ was under control. Fig. 6 presents the eco-efficiency of environmental pressure indicators as relative values. The eco-efficiency of dust obviously increased with an average annual growth of $18.9 \%$. The efficiency of wastewater, COD, AN rose by $36 \%, 22.1 \%, 38 \%$ in six years, respectively. The performance of $\mathrm{NO}_{\mathrm{x}}$ and solid waste kept steady, while the eco-efficiency of $\mathrm{SO}_{2}$ steadily increased until 2010 and then declined in the last three years. Compared with 2008, the eco-efficiency of $\mathrm{SO}_{2}$ decreased by $11.1 \%$ in 2013. With respect to solutions for environmental management, the Yichun government has required the pollution intensive companies to sign an agreement for pollution reduction. WFISG is the main target for pollution control. The major synergies can be found in the WFISG iron and steel complex that annually treat 550,000 tons of blast-furnace slag, 300,000 tons of scrap steel slag and 10,000 tons of dust (Yichun DRC, 2008). Besides, a waste incineration power plant is in operation which can treat waste at the amount of 400 tons per day. The heat generated by incineration can be supplied for heating in companies. The dust through electricity generation in the waste incineration plant can be recovered to produce construction materials.

(Fig.6 is inserted here.)

Overall, most indicators except for $\mathrm{SO}_{2}$ have kept improving in Yichun. It is a good sign that Yichun's eco-efficiency has not degenerated over time, far from it. However, the performance of Yichun's ecoefficiency still lags far behind the average level of Heilongjiang province. Bai et al. (2011) evaluated the eco-efficiency of 13 municipal cities in Heilongiiang province and found that Yichun ranked last. This is caused by its underdeveloped economy and low technical efficiency (Bai et al., 2011). We also find that the absolute values of resource consumption and environmental pressure are fair in Yichun, while the values of eco-efficiency indicators are tied down by the backward GDP. Indeed, Yichun's city government is aware of the challenges. Measures have been taken to deal with its slow economic and ecological progress, but the results are not very significant. In the next section, we will analyze the barriers that hinder the sustainable development in Yichun.

\subsection{Barriers in Yichun's transition towards sustainable development}

This section will discuss the barriers in Yichun's transition. We acquired the details from our interviews. This first-hand information is useful to understand the difficulties for Yichun's transformation. In the interviews, we detected three main problems: 1) difficulties in the industrial transformation, 2) conflicts on environmental policies, 3) limited impact of the circular economy approach.

\subsubsection{Difficulties in the industrial transformation}

As the complete prohibition of logging was issued in 2014, the whole forest industrial chain has shrunk markedly. $75 \%$ of forest product companies have closed, adding 35,000 laid-off workers to the already high total of unemployed. The direct loss from timber sales is over 0.7 billion RMB (Yichun DRC, 2014b). The output value of forestry industry decreased by $36 \%$. In 2013, Yichun's financial deficit was 8.52 billion RMB and $83.5 \%$ of its financial expenditure relied on the subsidies from higher governments (Yichun DRC, 2014b). The supportive policies from higher governments for Yichun's transition can ease the difficulties to some extent. For instance, the subsidies from the natural forest protection project for compensating local workers have been given to Yichun, but the one-time resettlement fund only provides 15,000 RMB per person for 134,000 people. 15,000 people are still on 
the waiting list (Yichun DRC, 2014b). To adjust its industrial structure, Yichun has promoted (1) mining and metallurgy, (2) forest food, and (3) ecological tourism as three new pillar industries. Meanwhile other industries, such as equipment manufacturing and clean energy, are also facilitated. But the scale of these alternative industries is not big enough to make up for the recession in the forestry industry. For instance, Yichun is striving to develop molybdenum mineral mining. However, Yichun's current technological capacity and industrial foundation are still weak. Mining relies on resource extraction that has low added value and high risks of pollution from wastewater, waste gas and heavy metal. Indeed, expanding the secondary industries requires large consumption of water, energy and resources, and meanwhile generates serious new pollution. Actually related pollution problems have already began to become apparent in Yichun. As the economy was stimulated after 2000 , the amount of coal consumption increased by $28 \%$ in 2005 compared with 2004 . The emission of industrial dust and $\mathrm{SO}_{2}$ increased by $5.4 \%$ and $14.97 \%$ in 2005, respectively (Yichun, 2008). In 2014, 18 companies in Yichun are monitored by the Ministry of Environmental Protection as the key sources emitting wastewater, waste gas and heavy metal into the environment. These companies are among the important alternative industrial sectors Yichun is promoting, involving steel manufacturing and mining. The industrial production brought about by this new secondary industry has obviously brought with it very new challenges to environmental quality. Industrial transformation should not blind us from remaining alert to trends in resource utilization, energy efficiency and pollution control.

\subsubsection{Conflicts on environmental policies between higher government and local context}

In China, environmental protection and pollution control are mainly driven by government initiatives. The national policies or plans (e.g., National $12^{\text {th }}$ Five-Year Plan for Environmental Protection) are made by the Ministry of Environmental Protection and the State Council. Policies are often implemented via a top-down approach from national government, to provincial and municipal government. The higher government divides the policy tasks (e.g., percentage of pollution reduction or energy conservation) for each local government. However, the implementation of environmental policies at the local level is premised on sufficient revenue, employment and industrial development. The goals made by central and provincial government may cause conflicts with local conditions, which require coordination and adjustment.

With respect to pollution control and energy conservation, Yichun's EPB and DRC have tried to reach the goals formulated by Heilongjiang provincial EPB and DRC. However, one-size-fits-all policies are unsuitable for Yichun. The missions regarding pollution control and energy consumption from the provincial government do not take Yichun's local situation into consideration. To reduce $\mathrm{NO}_{\mathrm{x}}$ emission, Heilongjiang provincial EPB has required Yichun's EPB to eliminate 10,000 vehicles not meeting the exhaust emission standards. This requirement is implemented through administrative means without offering other supportive policies (e.g., economic compensation for scrapped vehicles or exchanging them for higher standard vehicles), making it extremely hard for Yichun to implement them effectively. Moreover, provincial funds are assigned to other cities rather than Yichun, because the absolute values of total emissions in Yichun are lower than those of others. But Yichun's financial revenue lags way behind that of other municipal cities in Heilongjiang, and it cannot afford to spend much on environmental protection and energy conservation. Furthermore, the promotion of new energy leads to conflicts with forestry land policy. Yichun municipal government has stimulated new energy since 2005. Several wind farms have opened since then and now generate wind power. According to the new terms of forestry land policy issued by the National Forest Bureau in 2013, the wind farms in Yichun are not allowed to be built nearby forestry land. All the new wind power projects are on hold and the investors are awaiting an administrative solution. Therefore, the policies 
for improving environmental performance and energy conservation remain ineffective due to failing coordination between higher governments and Yichun's local government.

\subsubsection{Limited impact of the circular economy approach}

The circular economy has been proposed as an approach to increase the efficiency of resource consumption and pollution control in RBCs (Dong et al., 2007; Li et al., 2010). Yichun has made efforts to accelerate the realization of a circular economy in eight industrial parks. The industries chosen involve iron and steel, construction materials, furniture manufacturing, metallurgy and forest food. Nevertheless, the effects of the circular economy in Yichun are still limited. Several barriers inhibit good performance. On the one hand, the scale of the industrial parks is so small that they do not have an industrial basis to deliver significant results. The current synergies to reuse waste or byproducts are mainly inside one anchor tenant (e.g., WFISG). All still hinges on traditional upstream and downstream chains rather than a systematic implementation of the circular economy. The symbiosis network aimed at utilizing energy and by-products from different industrial sectors does not generate obvious results. On the other hand, the management of industrial parks is not institutionalized. A specialized administrative office and a standard management system have not been established for industrial park planning, project recruitment, infrastructure building and environmental supervision. They are in the early stages in the sense that companies simply decide simply to settle nearby without specialized services for approval procedures, environmental evaluation, finance and land use. The institutional mechanisms for the formulation of incentive policies and regulations that the circular economy requires are absent. For instance, the subsidy for installing online monitoring facilities was only given to the first batch of companies to reimburse $60 \%$ of their installation costs, while the rest companies did not get the subsidy. Besides, companies are encouraged to obtain ISO 14,000 certificates, but neither provincial nor municipal government has provided concrete policy instruments to stimulate company participation in doing this. Without long-term institutional mechanisms for the circular economy, any other incentives from governments are bound to remain ineffective. Companies would hesitate to engage in environmentally promising initiatives due to high but uncertain upfront investments in technical renovation for pollution prevention.

\section{Discussion and conclusions}

Yichun's case has revealed a number of key barriers RBCs face to go down the path of sustainable development. It appears that Yichun is trapped in a vicious circle. Due to the over-dependence on the forestry industry, its industrial foundation for other industrial sectors has remained underdeveloped. The deforestation and prohibition orders for cutting have caused a steep decline in its timber industry, which at its turn resulted in a large public deficit and massive unemployment. Meanwhile, the alternative industries are too immature to make up for the financial loss. The main new contributors to local GDP, such as the iron and steel and construction material industries, are pollution-intensive and energy-intensive. However, Yichun's financial situation does not allow spending much on stimulating companies to control their pollution. Neither are the related personnel, technologies and institutions in place to implement comprehensive environmental supervision and management. Moreover, the new energy projects for improving the efficiency of energy consumption cannot be performed due to the conflicting policies. Thus, the effects of environmental management are not leading to an improvement in eco-efficiency that otherwise should have been possible. The example of Yichun has revealed some general features of RBCs. In their transformation, all RBCs experience a tough period of economic recession as natural resources become exhausted. The main solution is to promote alternative industries or improve the competitiveness of current resource based industries. For instance, environmental regulation in the Ruhr was strictly implemented based on a series of laws for air quality 
monitoring, source control and emission treatment. It was achieved through national legislation for environmental protection, economic policy instruments such as subsidies and taxes, and the adjustment of industrial structures (Hassink and Shin, 2005). Similar patterns of economic and environmental transition also happened in many other RBCs, such as the steel cities of Pittsburgh in the US and Lorraine in France. The lessons of these successful RBCs can be learned by Yichun when formulating the strategies and goals for its transformation. But the main complication in Yichun is ineffective intergovernmental policy making and implementation.

Based on the barriers we found in Yichun's case, we propose the following recommendations to facilitate its sustainable development. First, regarding the industrial transformation, Yichun needs to be selective when allowing in alternative industries, however tempting these might be. On the one hand, the energy-intensive and pollution-intensive industries (e.g., iron and steel production) that are in the national catalogues of backward production capacities should be shut down. But ones with efficient production facilities and large production capacity cannot be eliminated overnight, due to Yichun's current level of economic development. After all, Yichun is still in recession. Meanwhile, the environmental management tools, such as cleaner production and energy audits, should be absolute requirements for these companies to improve the efficiency of their resource consumption and pollution prevention. Precepts on realizing the circular economy should be systematically considered in the planning of infrastructures and industrial layout, especially in industrial parks. On the other hand, industries that have low environmental pressure and high added value should be attracted with priority. Yichun has made efforts in recruiting them, such as in the high tech food and medicine industries. Apart from introducing these projects, the related talents and industrial chains are all needed to be fostered together. Second, the policies and requirements from higher government need to consider Yichun's local situation far more carefully. One-size-fits-all policies do not help to solve the key problems in Yichun. Policies for a transition towards sustainable development involve various departments within the local government and provincial governments. These need to be better coordinated if authorities actually want them to be effectively implemented. Subsidies from higher tiers of government are indispensable to help Yichun in its transition. The national and provincial government may step up their preferential policies to facilitate Yichun's alternative industries through industrial deployment, tax reduction, loans and financing, land use, and research. The activities of industries and inhabitants all influence its ecological environment. Apart from the improvement of environmental performance in industries, the consumption patterns of inhabitants also matter in raising awareness for the importance of ecological protection in forested areas. Forests are an essential component in a forestry city as an ecological-economic system, rather than just as a resource for production. The ecological functions of urban forest (e.g., carbon sequestration and microclimate improvement) should be taken into account in the policies for improving Yichun's economy. Therefore, the sustainable consumption of inhabitants and prosperity of community are important to brand Yichun's eco-development especially for ecological tourism.

In this article, we focused on policy dilemmas that RBCs face on their path towards sustainable development. Sustainable consumption and production in RBCs is critical, due to their tight interrelations with natural resources and ecological systems. Limitations still exist in our research. Yichun is particular because of the historical dominance of its forestry industry, while other types of RBCs have their own features due to the evolution of different resource-based industries. Nonetheless the challenges when having to consider both economic and environmental aspects in this transformation and the tensions between various interest and regulations derived from various public authorities during policy implementation are common among all RBCs. Thus, the lessons learned from Yichun are, mutatis mutandis, useful for other RBCs and their transition in the direction of sustainable 
development. It may take some time to solve many of the dilemmas and various rounds of policy adjustment may be required. During this process, even if economic growth remains the highest priority among RBCs, ignoring the principles of sustainable development will lead to very serious long-term new problems of pollution and energy consumption. Reckless admission of new but polluting industries generating high initial profits is likely to generate a need for "treatment after pollution" measures that prove even more expensive in the long term.

\section{Acknowledgements}

This work was supported by the projects of Forestry Commonweal Program (No. 201404422) and National Science Foundation of China (No. 71203011) at Beijing Forestry University. We greatly appreciate the assistance from Yichun Environment Protection Bureau, Development and Reform Commission, Industry and Information Commission.

\section{References:}

Bai, S., Wang, Z., Zhang, J., Liu, M., 2011. Evaluating the eco-efficiency of Heilongjiang province with DEA approach, E -Business and E -Government (ICEE), 2011 International Conference on. IEEE, Shanghai, China, pp. 1-4.

Bradbury, J.H., 1979. Towards an Alternative Theory of Resource-Based Town Development in Canada. Economic Geography 55, 147-166.

Bradbury, J.H., St-Martin, I., 1983. Winding Down in a Quebec Mining Town: a Case Study of Schefferville. Canadian Geographer / Le Géographe canadien 27, 128-144.

Clark, G., 2007. Evolution of the global sustainable consumption and production policy and the United Nations Environment Programme's (UNEP) supporting activities. Journal of Cleaner Production 15, 492-498.

de Jong, M., Yu, C., Chen, X., Wang, D., Weijnen, M., 2013. Developing robust organizational frameworks for Sino-foreign eco-cities: comparing Sino-Dutch Shenzhen Low Carbon City with other initiatives. Journal of Cleaner Production 57, 209-220.

Dong, S., Li, Z., Li, B., Xue, M., 2007. Problems and Strategies of Industrial Transformation of China's Resource-based Cities. China Population, Resources and Environment 17, 12-17.

Hassink, R., Shin, D.-H., 2005. The restructuring of old industrial areas in Europe and Asia. Environment and Planning A 37 (4), 571-580.

Huppes, G., Ishikawa, M., 2005. A framework for quantified eco-efficiency analysis. Journal of Industrial Ecology 9, 25-41.

Koskela, M., 2015. Measuring eco-efficiency in the Finnish forest industry using public data. Journal of Cleaner Production 98, 316-327.

Li, H., Long, R., Chen, H., 2013. Economic transition policies in Chinese resource-based cities: An overview of government efforts. Energy Policy 55, 251-260.

Li, H., Long, R., Lan, X., 2010. Assessment for Eco-efficiency of Resource-based Cities. Resources Science 32 (7), 1296-1300.

Liu, Y., Yin, G., Ma, L.J.C., 2012. Local state and administrative urbanization in post-reform China: A case study of Hebi City, Henan Province. Cities 29, 107-117.

Long, R., Chen, H., Li, H., Wang, F., 2013. Selecting alternative industries for Chinese resource cities based on intra- and inter-regional comparative advantages. Energy Policy 57, 82-88.

Lucas, R.A., 1971. Minetown, Milltown, Railtown: life in Canadian communities of single industry. University of Toronto Press.

SFA, 2000. Natural forest protection project in the state-owned forestry districts in Northeastern regions and Inner Mongolia issued by State Forestry Administration (SFA).

Percy, S., 2003. The Ruhr: From Dereliction to Recovery, in: Couch, C., Fraser, C., Percy, S. (Eds.), Urban Regeneration in Europe. Blackwell Science Ltd, Oxford, UK.

Sachs, J.D., Warner, A.M., 2001. The curse of natural resources. European Economic Review 45, 827838 . 
Schroeder, P., 2014. Assessing effectiveness of governance approaches for sustainable consumption and production in China. Journal of Cleaner Production 63, 64-73.

Seppäläa, J., Melanen, M., Mäenpää, I., Koskela, S., Tenhunen, J., Hiltunen, M.-R., 2005. How Can the Eco-efficiency of a Region be Measured and Monitored? Journal of Industrial Ecology 9, 117-130.

State Council, 2007. Suggestions for promoting sustainable development of resource-based cities. Retrieved 25 July, 2015, from http://www.gov.cn/zwgk/2007-12/24/content_841978.htm.

State Council, 2013. Planning of sustainable development of resourced-based cities from 2013 to 2020. Retrieved 25 July, 2015, 2015, from http://www.gov.cn/zwgk/2013-12/03/content 2540070.htm.

Tian, J., Liu, W., Lai, B., Li, X., Chen, L., 2014. Study of the performance of eco-industrial park development in China. Journal of Cleaner Production 64, 486-494.

Tukker, A., Sto, E., Vezzoli, C., 2008. "The governance and practice of change of sustainable consumption and production." Introduction to the ideas and recommendations presented in the articles in this special issue of the journal of cleaner production. Journal of Cleaner Production 16, 1143-1145.

Wang, Y., Liu, J., Hansson, L., Zhang, K., Wang, R., 2011. Implementing stricter environmental regulation to enhance eco-efficiency and sustainability: a case study of Shandong Province's pulp and paper industry, China. Journal of Cleaner Production 19, 303-310.

Wang, Y., Sun, M., Wang, R., Lou, F., 2015. Promoting regional sustainability by eco-province construction in China: A critical assessment. Ecological Indicators 51, 127-138.

Wu, F., 2012. China's eco-cities. Geoforum 43, 169-171.

Yichun, 2008. The 11th five-year plan of environmental planning in Yichun. Retrieved 25 July, 2015, from http://www.yhb.gov.cn/Item/266.aspx.

Yichun, 2009. Planning of ecological functional zone in Yichun. Retrieved 25 July, 2015, from, http://www.yc.gov.cn/zwgk/ghjh/ztgh/2009/09/31851.html.

Yichun DRC, 2008. Planning of circular economy in Yichun from 2008 to 2020.

Yichun DRC, 2014a. Report about new energy development in Yichun.

Yichun DRC, 2014b. Report about the sustainable development in Yichun.

Yichun EPB, 2014. Report on the progress of Yichun's environmental responsibility indicators.

$\mathrm{Yu}$, J., Zhang, W., Wang, D., 2011. The transformation path of China's resource-exhausted cities. World regional studies 20 (3), 62-72.

Yu, J., Zhang, Z., Zhou, Y., 2008. The sustainability of China's major mining cities. Resources Policy 33, 12-22.

Yu, Y., Chen, D., Zhu, B., Hu, S., 2013. Eco-efficiency trends in China, 1978-2010: Decoupling environmental pressure from economic growth. Ecological Indicators 24, 177-184.

Zhang, L., Yuan, Z., Bi, J., Zhang, B., Liu, B., 2010. Eco-industrial parks: national pilot practices in China. Journal of Cleaner Production 18, 504-509. 


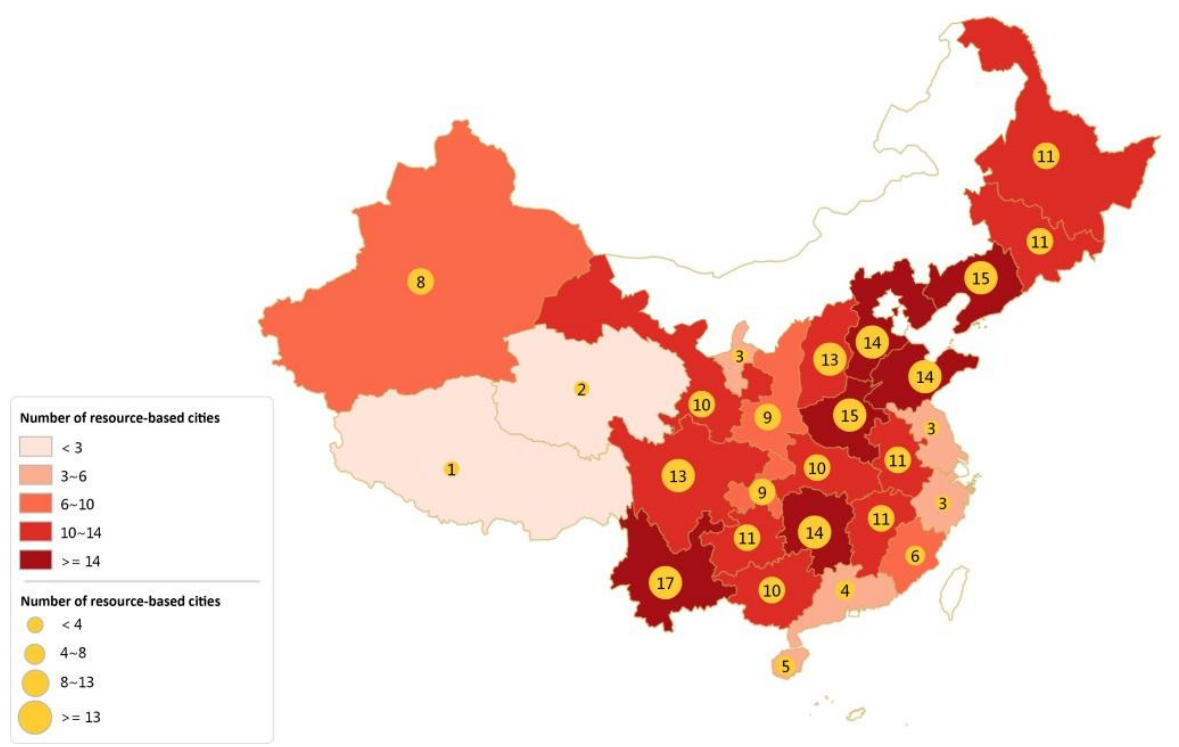

Fig 1. Distribution of RBCs in China. Data source: (State Council, 2013). 


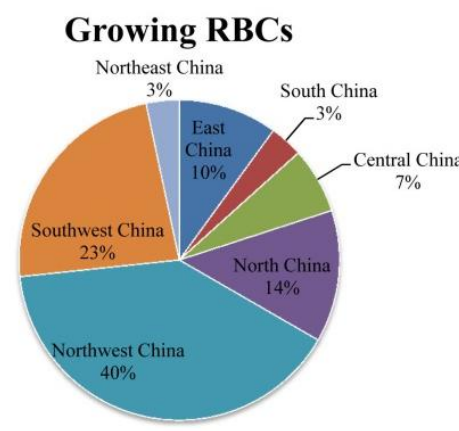

Recessionary RBCs

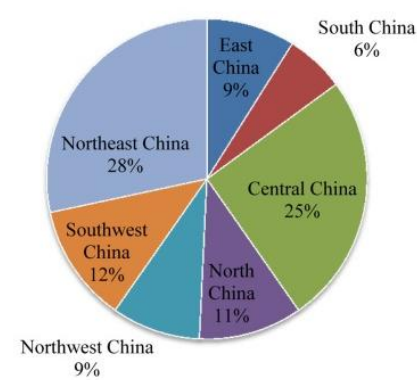

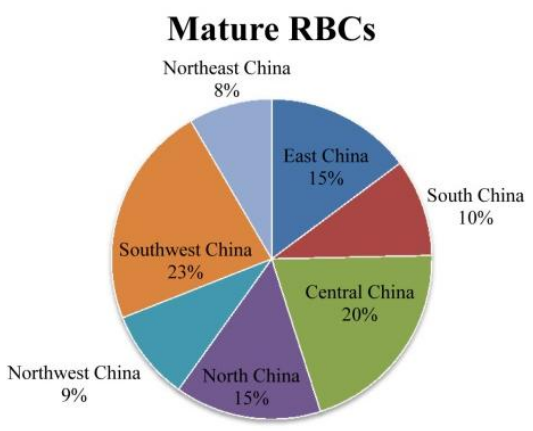

Recovered RBCs

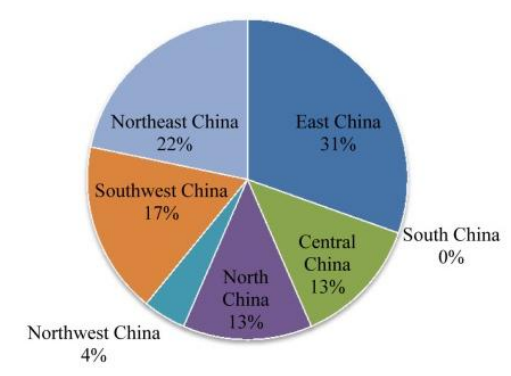

Fig 2. Proportion of four types of RBCs in the different parts of China. Data source: (State Council, 2013). 


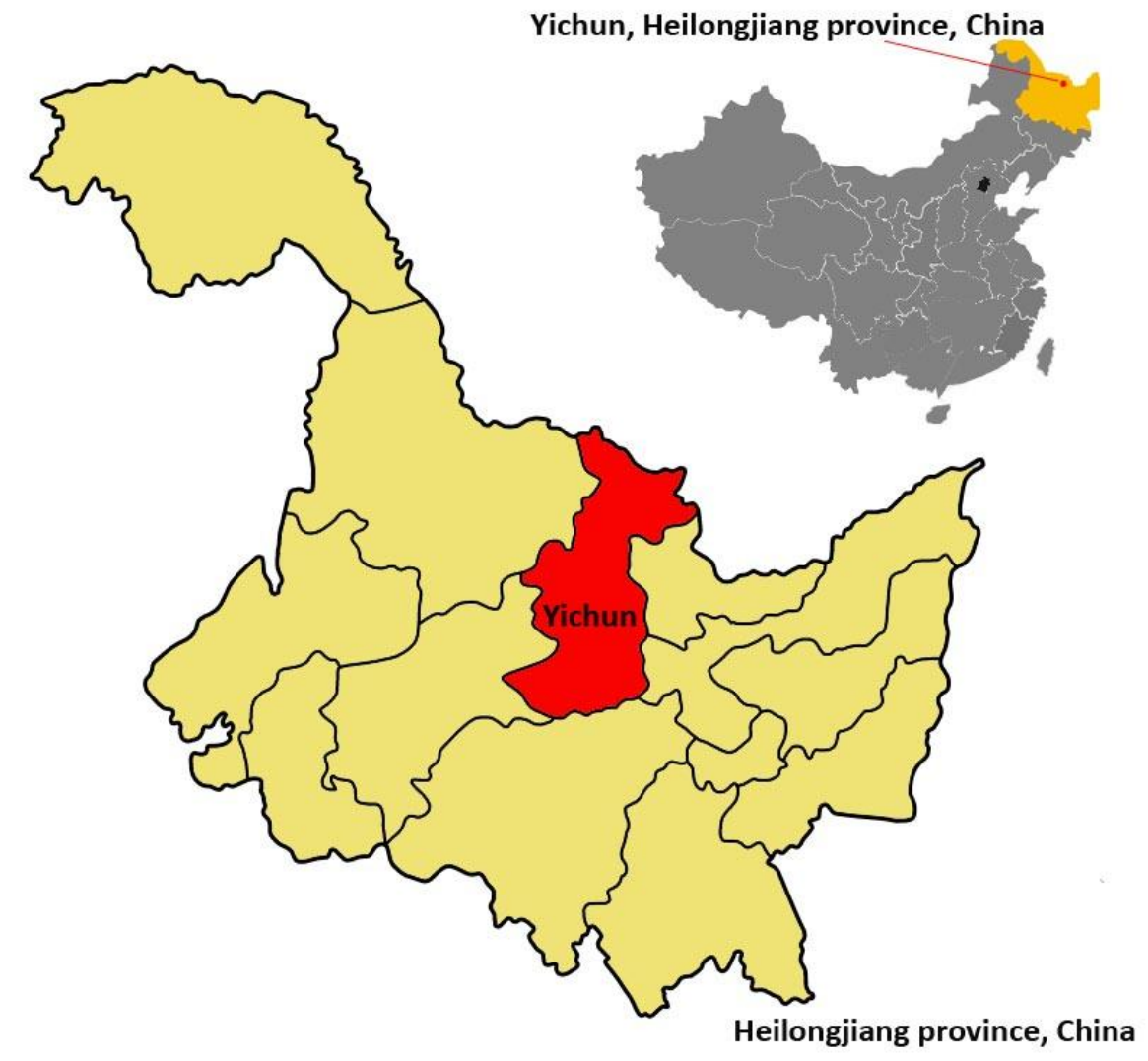

Fig 3. Geography of Yichun in Helongjiang province, China. 


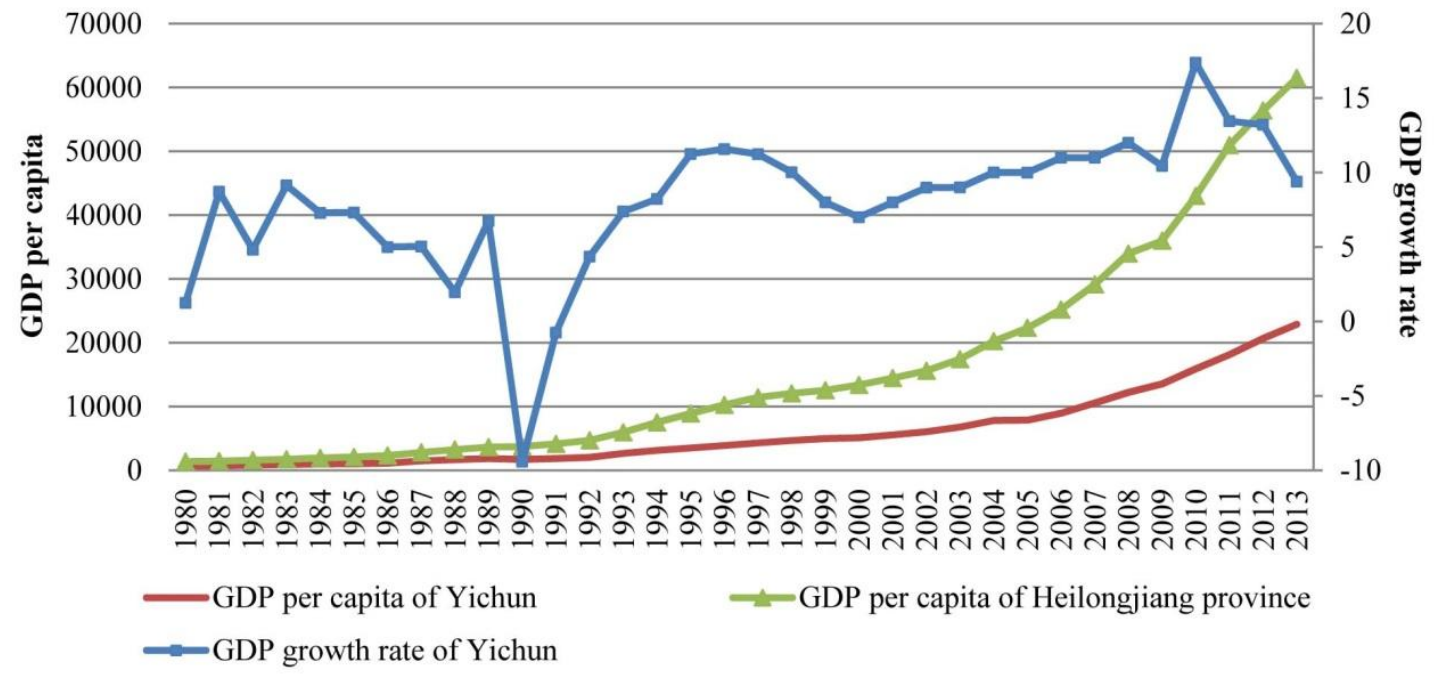

Fig 4. Annual GDP growth rate and GDP per capita of Yichun city. Unit of GDP: billion RMB. Unit of GDP per capita: RMB. Data sources: Yichun Statistical Yearbooks (2010-2013), Yearbooks of Development of Heilongjiang During 60 Years (1949-2009), and Heilongjiang Statistical Yearbooks (1980-2013). 


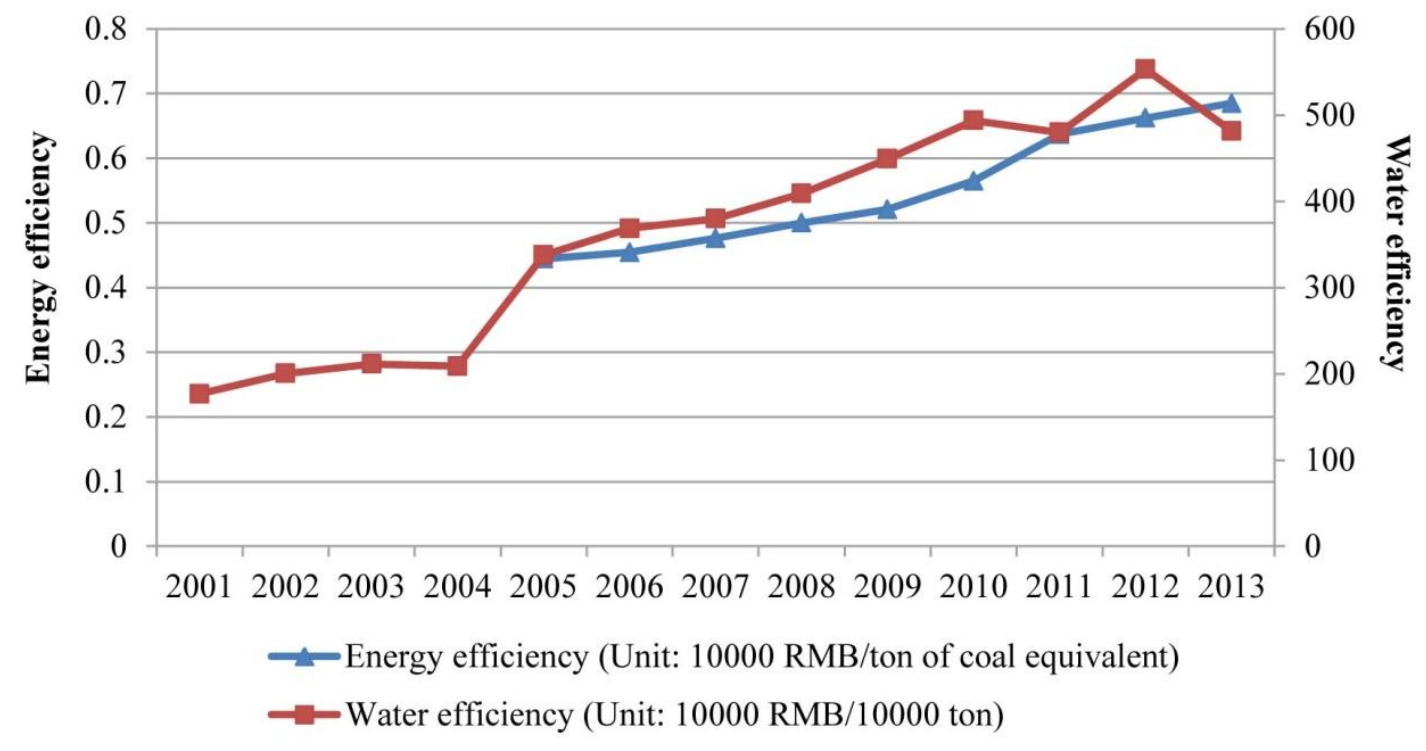

Fig 5. Energy efficiency between 2005 and 2013 and water efficiency between 2001 and 2013. 


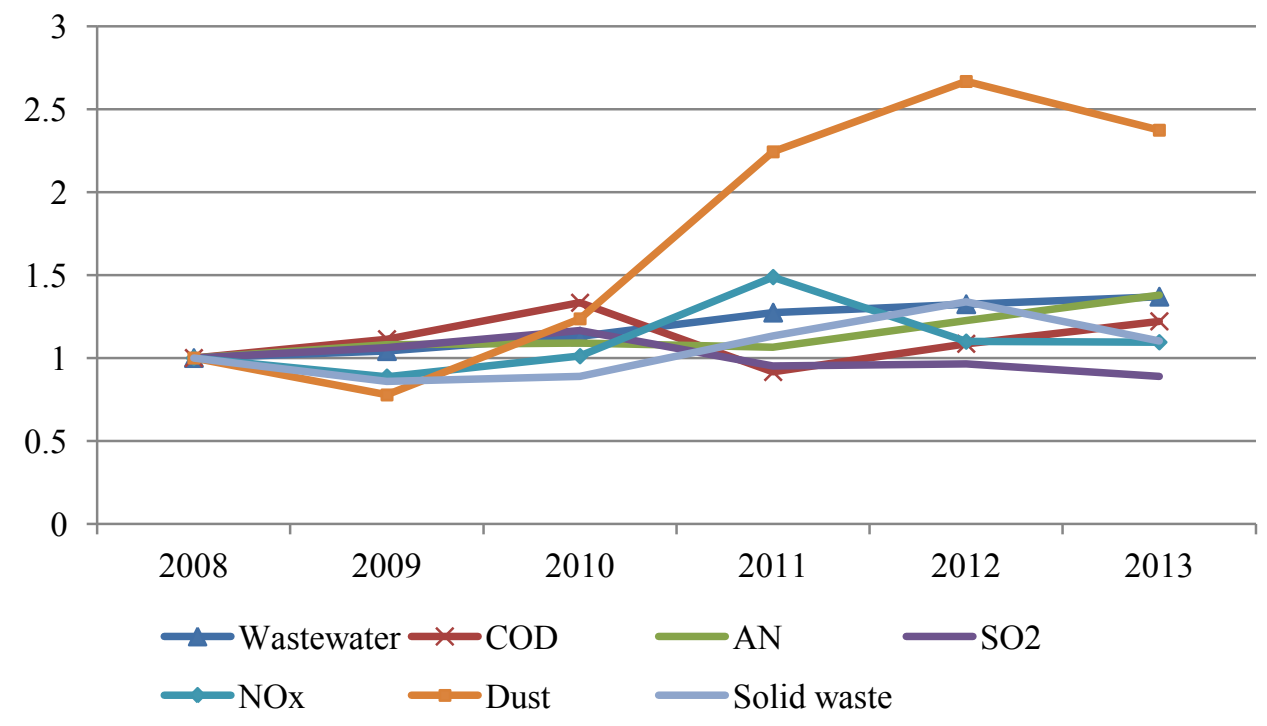

Fig. 6. Efficiency of wastewater, $\mathrm{COD}, \mathrm{AN}, \mathrm{SO}_{2}, \mathrm{NO}_{\mathrm{x}}$, dust and solid waste between 2008 and 2013. 
Table 1. Regional policies for Ruhr's transformation in the different periods (Percy, 2003)

\section{Period of}

Regional policies

\section{transformation}

\begin{tabular}{|c|c|}
\hline $\begin{array}{l}\text { 1950s--1960s, } \\
\text { recession due to the } \\
\text { decline of coal } \\
\text { industry. }\end{array}$ & $\begin{array}{l}\text { Establishing Ruhr District Association of Communities (KVR) to } \\
\text { coordinate regional planning for regenerating the area and improving } \\
\text { the environmental conditions. }\end{array}$ \\
\hline $\begin{array}{l}\text { 1960s--1970s, } \\
\text { restructuring } \\
\text { traditional coal and } \\
\text { steel industry }\end{array}$ & $\begin{array}{l}\text { Issuing "Ruhr Development Program" that aimed at modernizing the } \\
\text { level of technology of coal and steel industry and merging coal } \\
\text { companies; Building infrastructures for public transport and } \\
\text { environmental treatment; Promoting research institutes and } \\
\text { universities for technology innovation. }\end{array}$ \\
\hline $\begin{array}{l}\text { 1970s--1980s, } \\
\text { fostering } \\
\text { industries. }\end{array}$ & $\begin{array}{l}\text { Issuing "Ruhr Area Action Program" that provided financial } \\
\text { resources to establish an energy center, attract biotechnology and } \\
\text { other innovative technology companies. }\end{array}$ \\
\hline $\begin{array}{l}\text { 1980s--late1990s, } \\
\text { regional collaboration } \\
\text { and integration. }\end{array}$ & $\begin{array}{l}\text { Issuing "Coal and Steel Regions Initiative for the Future" that aimed } \\
\text { at regional collaboration; Setting up "International Building } \\
\text { Exhibition (IBA) Emscher Park" to promote ecological recovery, } \\
\text { environmental treatment and the tourist industry. }\end{array}$ \\
\hline $\begin{array}{l}2000 \text { until now, } \\
\text { enhancing } \\
\text { competitive industries } \\
\text { and regional } \\
\text { integration. }\end{array}$ & $\begin{array}{l}\text { Issuing "Project Ruhr GmbH program" that targeted } 12 \text { competitive } \\
\text { industries (including energy, logistics and cultural tourist) to boost } \\
\text { economy and employment; Issuing "European Cultural Capital } \\
\text { Program" to collaborate adjacent cities. }\end{array}$ \\
\hline
\end{tabular}


Table 2. Roles and goals of four types of resource-based cities for sustainable development.

\begin{tabular}{|c|c|c|c|}
\hline RBC Type & Number & Roles & Goals \\
\hline Growing & 31 & $\begin{array}{lr}\text { Strategic } & \text { base } \\
\text { energy } & \text { and } \\
\text { resource } & \text { supply } \\
\text { and storage. } & \end{array}$ & $\begin{array}{l}\text { Enhance threshold of resource } \\
\text { exploiting enterprises; } \\
\text { Strengthen environmental impact } \\
\text { assessment; } \\
\text { Internalize environmental cost; } \\
\text { Deep process natural resources and } \\
\text { promote supporting industries; } \\
\text { Coordinate resource exploitation and } \\
\text { urbanization. }\end{array}$ \\
\hline \multirow[t]{3}{*}{ Mature } & \multirow[t]{3}{*}{141} & \multirow{3}{*}{$\begin{array}{l}\text { Core regions of } \\
\text { current energy and } \\
\text { resource supply. }\end{array}$} & $\begin{array}{l}\text { Improve technologies of exploitation } \\
\text { and extend industrial chains; }\end{array}$ \\
\hline & & & $\begin{array}{l}\text { Foster anchor companies and } \\
\text { industrial cluster; }\end{array}$ \\
\hline & & & $\begin{array}{l}\text { Form multiple alternative industries; } \\
\text { Enhance livelihood and public } \\
\text { service; Improve urban functions and } \\
\text { quality of urbanization. }\end{array}$ \\
\hline
\end{tabular}

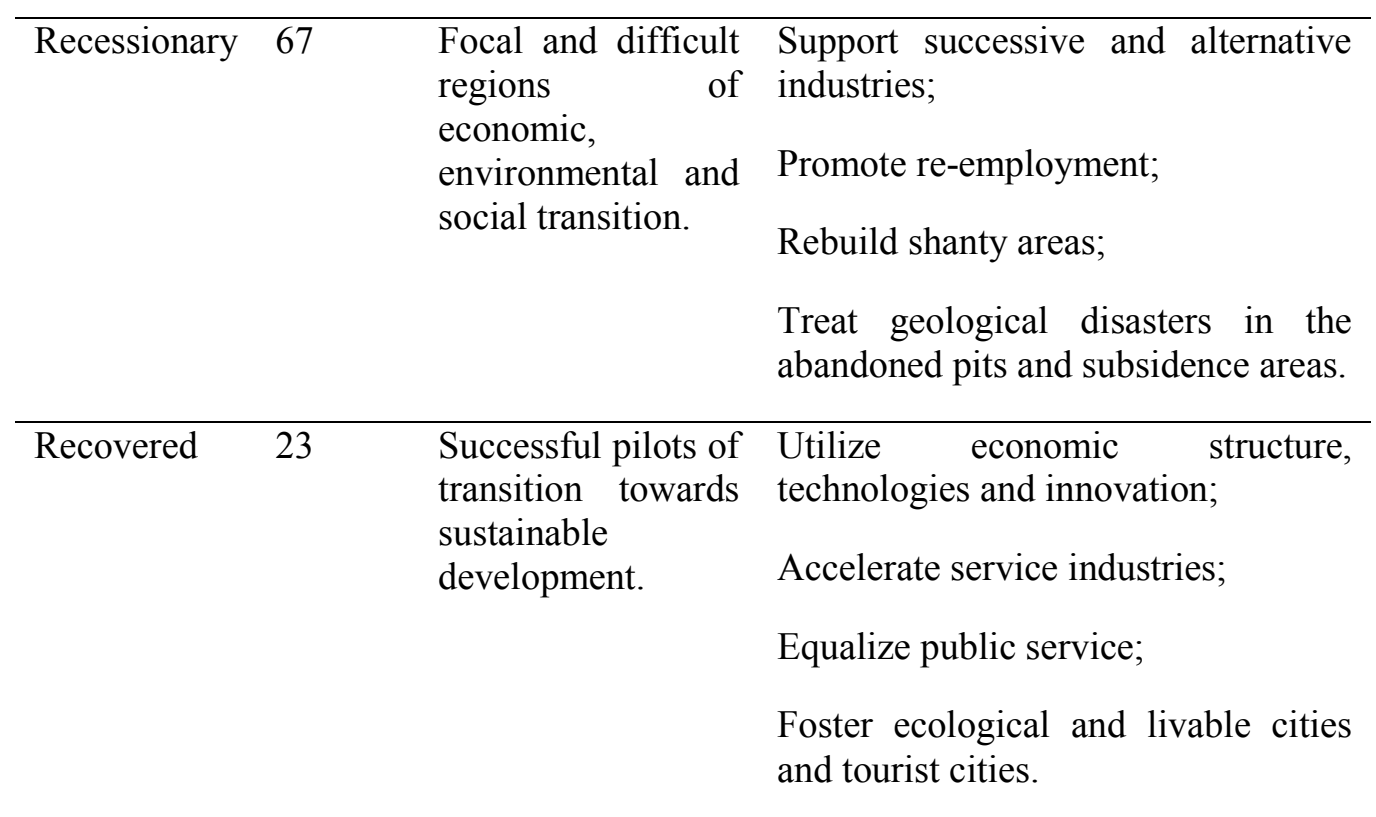


Table 3. Stages of Yichun's development.

\begin{tabular}{ll}
\hline \multicolumn{1}{c}{$\begin{array}{c}\text { Stages of Yichun's } \\
\text { development }\end{array}$} & \multicolumn{1}{c}{ Status } \\
\hline 1948--1958, establishment. & Yichun city was established based on forestry industry. \\
\hline 1958--1980, prosperity. & $\begin{array}{l}\text { GDP and employment constantly increased due to vast } \\
\text { extractive industry and timber production. }\end{array}$ \\
\hline $\begin{array}{l}\text { 1980--1994, economic crisis } \\
\text { and recession. }\end{array}$ & $\begin{array}{l}\text { Severe deforestation caused a shrink in the forestry industry } \\
\text { and employment. Ecology and environment were damaged. }\end{array}$ \\
\hline $\begin{array}{l}\text { 1994--present, recession } \\
\text { slight recover. }\end{array}$ & $\begin{array}{l}\text { Alternative industries were stimulated, but the economic } \\
\text { output cannot make up for the loss of the forestry industry. } \\
\text { Prohibition orders against logging bring new challenges } \\
\text { with them. }\end{array}$ \\
\hline
\end{tabular}


Appendix. Departments of interviewees and the questions for interviews.

\begin{tabular}{|c|c|}
\hline $\begin{array}{l}\text { Departments } \\
\text { of } \\
\text { interviewees }\end{array}$ & $\begin{array}{l}\text { 1. Yichun Foresty Administration. } \\
\text { 2. Yichun Environment Protection Bureau. } \\
\text { 3. Yichun Development and Reform Commission. } \\
\text { 4. Yichun Industry and Information Commission. } \\
\text { 5. Municipal office of industrial transformation. } \\
\text { 6. } \\
\end{array}$ \\
\hline $\begin{array}{l}\text { Main } \\
\text { interview } \\
\text { questions }\end{array}$ & $\begin{array}{l}\text { - How have the alternative industries been stimulated since the prohibition } \\
\text { orders of logging were issued? How do the alternative industries perform? } \\
\text { - What are the major sources of pollution in Yichun? } \\
\text { - What kinds of measures have been employed to reduce pollution? } \\
\text { - How have the companies been simulated to conduct cleaner production? } \\
\text { - What kinds of barriers are there to implement environmental policies? }\end{array}$ \\
\hline
\end{tabular}

